\title{
A prediction model for water breakthrough time in high-sulfur gas reservoir with edge water
}

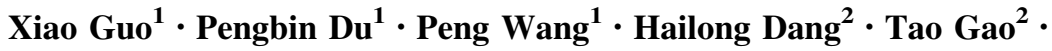 \\ Ge Song ${ }^{3}$
}

Received: 2 May 2017/Accepted: 23 July 2017/Published online: 1 August 2017

(c) The Author(s) 2017. This article is an open access publication

\begin{abstract}
The water coning phenomenon leads to decrease the wellhead pressure with moving of water into gas production zone, which is regarded as one of most serious problems during gas production. It has been shown that water breakthrough time plays an important role in analyzing the water coning phenomenon and production of water. However, the existing prediction models of water breakthrough time are very scarce and need to be discussed. In this work, a novel model for water breakthrough time in high-sulfur gas reservoir with edge water is developed based on flow law and sulfur precipitation model in porous media. The effect of irreducible water saturation, residual gas saturation, and the distance between gas well and edge water, sulfur saturation and gas non-Darcy flow on water breakthrough time was involved in this model. The validity of the proposed model is verified by comparing the existing models available. A good trend is found between them. In addition, the influence of the distance between gas well and edge water, sulfur saturation and gas non-Darcy flow on water breakthrough time was detail discussed further.
\end{abstract}

Peng Wang

wang_pengsss@163.com

1 State Key Laboratory of Oil and Gas Reservoir Geology and Exploitations, Southwest Petroleum University, Chengdu 610500, China

2 Research Institute of Yanchang Petroleum (Group) Co. LTD, Xi' an 710075, China

3 Northeastern Sichuan Gas Recovery Plant of Sinopec Southwest Petroleum Company, Langzhong 637400, China
Keywords High-sulfur gas reservoir · Water breakthrough time $\cdot$ Edge water $\cdot$ Sulfur precipitation $\cdot$ Gas non-Darcy flow

\section{List of symbols}

$B_{\mathrm{g}} \quad$ Gas volume factor

c Sulfur solubility $\left(\mathrm{kg} / \mathrm{m}^{3}\right)$

$h \quad$ Reservoir thickness (m)

$k_{\mathrm{g}} \quad$ Gas-phase permeability $\left(\mu \mathrm{m}^{2}\right)$

$k_{\mathrm{w}} \quad$ Water-phase permeability $\left(\mu \mathrm{m}^{2}\right)$

$k_{\mathrm{a}} \quad$ Absolute permeability $\left(\mu \mathrm{m}^{2}\right)$

$k_{\mathrm{rg}} \quad$ Relative permeability $\left(\mu \mathrm{m}^{2}\right)$

$k_{\mathrm{rw}} \quad$ Relative permeability $\left(\mu \mathrm{m}^{2}\right)$

$k_{\mathrm{gwi}}$ Gas-phase permeability at initial irreducible water saturation $\left(\mu \mathrm{m}^{2}\right)$

$k_{\text {wgr }} \quad$ Water-phase permeability at residual gas saturation $\left(\mu \mathrm{m}^{2}\right)$

$L \quad$ Horizontal well horizontal length (m)

$m \quad$ Solid sulfur quality $\left(\mathrm{kg} / \mathrm{m}^{3}\right)$

$M_{\mathrm{a}} \quad$ Molecular weight of the dry air $(28.97 \mathrm{~kg} / \mathrm{kmol})$

$M_{\mathrm{gw}} \quad$ Gas-water mobility ratio

$p \quad$ Gas reservoir pressure (MPa)

$p_{\mathrm{g}} \quad$ Gas-phase pressure (MPa)

$p_{\mathrm{w}} \quad$ Water-phase pressure (MPa)

$P_{\mathrm{sc}} \quad$ Standard state pressure $(0.101325 \mathrm{MPa})$

$q \quad$ Gas well production $\left(\mathrm{m}^{3} /\right.$ day)

$r \quad$ Radius of gas reservoir (m)

$r_{\mathrm{a}} \quad$ Distance between point A and gas well (m)

$r_{\mathrm{w}} \quad$ Well radius $(\mathrm{m})$

$R \quad$ Conventional gas constant, 0.008315

$S_{\mathrm{wi}} \quad$ Irreducible water saturation

$S_{\mathrm{gr}} \quad$ Residual gas saturation

$S_{s} \quad$ Sulfur saturation in porous media

$t \quad$ Gas well water breakthrough time (day)

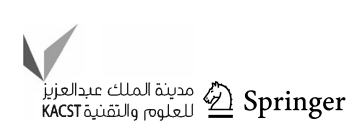


$T_{\mathrm{sc}} \quad$ Standard state temperature $(293 \mathrm{~K})$

$T \quad$ Reservoir temperature (K)

$\mu_{\mathrm{g}} \quad$ Gas-phase viscosity ( $\mathrm{Pa} \mathrm{s}$ )

$\mu_{\mathrm{w}} \quad$ Water-phase viscosity (Pa s)

$v_{\mathrm{g}} \quad$ Gas-phase velocity (m)

$v_{\mathrm{w}} \quad$ Water-phase velocity $(\mathrm{m})$

$V_{\mathrm{s}} \quad$ Solid sulfur volume $\left(\mathrm{m}^{3}\right)$

$Z \quad$ Deviation factor of natural gas

$Z_{\mathrm{sc}} \quad$ Standard state gas Z-factor, 1s

$\alpha \quad$ Empirical constant $(-6.22)$

$\beta \quad$ Turbulence coefficient $(1 / \mathrm{m})$

$\phi \quad$ Reservoir porosity

$\gamma_{\mathrm{g}} \quad$ Relative density of natural gas

$\rho_{\mathrm{s}} \quad$ Density of the solid sulfur $\left(2070 \mathrm{~kg} / \mathrm{m}^{3}\right)$

\section{Introduction}

Active edge water gas reservoir accounts for approximately $20-35 \%$ of water drive gas reservoirs and most of the gas reservoirs of China are at different degrees of water drive gas reservoirs. Most of the high-sulfur gas reservoirs are close to water bodies of edge water (Wang et al. 2011). During the development of high-sulfur gas reservoirs at water drive gas, the water body flows to the gas reservoir, forming a gas-water two-phase seepage with decreasing pressure. This results in a decrease in gas well recovery rate (Wang et al. 2011; Zeng et al. 2013; Li 2014; Liu et al. 2015; Yu et al. 2016). There is abundant evidence that water breakthrough time is one of the most key factors in analysis water coning phenomenon and production of water (Zhang et al. 2004; Li et al. 2015; Huang et al. 2016). However, the existing prediction models of water breakthrough time are very scarce and unavailable. Therefore, it is essential to obtain a prediction model for water breakthrough time in high-sulfur gas reservoir with edge water.

It is a scientific problem for edge water coning and gas well water breakthrough time. However, there are short studies on the methods of predicting water breakthrough time for edge water gas reservoir. For example, Wang et al. (2008) derived a formula to determine water breakthrough time of gas reservoirs with edge water through mathematical development. The formula considers the influential factors such as gas-water mobility ratio, initial irreducible water saturation, residual gas saturation, and the distance between gas well and edge water. Yang et al. (2013) developed a predicting water breakthrough time model in gas wells with the approximate straight line edge water supply based on flow law in porous media, considering non-Darcy effects of near wellbore area in high gas rate wells. Wu and $\mathrm{Li}$ (2013) proposed a new prediction formula of edge water breakthrough time based on fluid flow in porous media considering impact of anti-condensate. The effect of retrograde gas condensate on edge water breakthrough time was small. Although these models have been widely used in conventional oil/gas reservoirs, unfortunately, they cannot be suitable for high-sulfur gas reservoir with edge water. For high-sulfur gas reservoirs, the effect of sulfur deposition on edge water coning time should be considered.

In this paper, we focus our attention on the derivation of a novel model for edge water breakthrough time for high-sulfur gas reservoirs. In Sect. 2, based on the theory of gas water multiphase flow, we will establish this model considering sulfur deposition and gas high-speed non-Darcy flow effect. In addition, relevant model parameters are solved, so that the model can be better analyzed further. The validity of the proposed model is verified by comparisons between the present model predictions and those from the available model as well as existing field data, and the effects of parameters such as sulfur saturation and gas non-Darcy flow on water breakthrough time were detailedly discussed in Sect. 3. The conclusions from this work are given in Sect. 4.

\section{The establishment and solution of the model to water breakthrough time}

\section{The establishment of the model}

The physical model of edge water breakthrough is shown in Fig. 1.

Assumptions:

(1) Homogeneous reservoir distributes and sulfur of precipitation is not migration in reservoir;

(2) Water drives gas follows piston displacement;

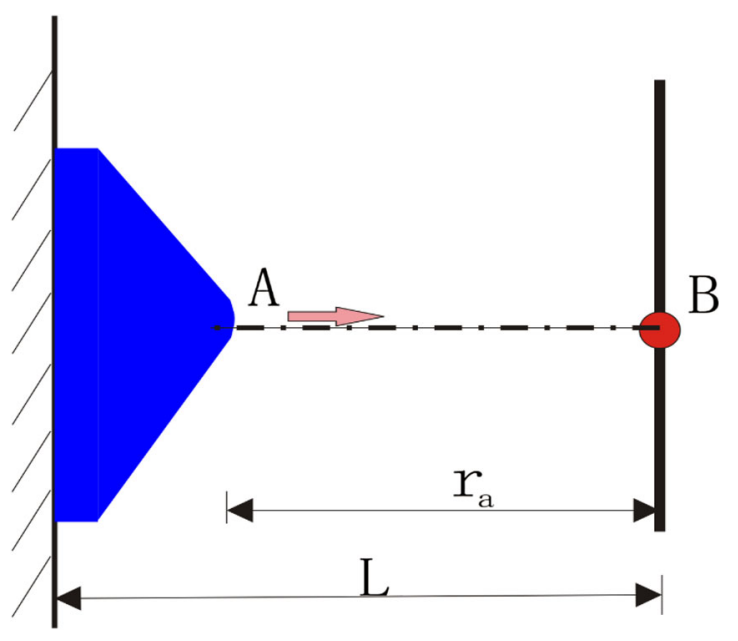

Fig. 1 Schematic diagram of water coning in edge water 
(3) Constant gas-water viscosity and deviation factor;

(4) Ignore capillary force, gravity, reservoir anisotropy and stress sensitivity, slippage, and skin factor effects during the displacement process;

Producing well B near gas-water boundary in highsulfur gas reservoir with edge water was assumed (Fig. 1). Distance of initial gas-water interface to gas well is L. There is a mass point $\mathrm{A}$ at initial gas-water interface, radial flowing toward gas well point B.

According to the theory of gas water two-phase flow, equation of gas-water motion is given in Eqs. (1) and (2), in which the gas phase takes into account the high-speed non-Darcy effect.

$\frac{\mathrm{d} p_{\mathrm{g}}}{\mathrm{d} r}=-\frac{\mu_{\mathrm{g}} v_{\mathrm{g}}}{k_{\mathrm{g}}}-\beta \rho_{\mathrm{g}} v_{\mathrm{g}}^{2}$

$\frac{\mathrm{d} p_{\mathrm{w}}}{\mathrm{d} r}=-\frac{\mu_{\mathrm{w}} v_{\mathrm{w}}}{k_{\mathrm{w}}}$

The pressure of point $\mathrm{A}$ at gas and water interface is equal; the following equation is obtained:

$$
\left(\frac{\mathrm{d} p_{\mathrm{g}}}{\mathrm{d} r}\right)_{r=r_{\mathrm{a}}}=\left(\frac{\mathrm{d} p_{\mathrm{w}}}{\mathrm{d} r}\right)_{r=r_{\mathrm{a}}}
$$

Combining Eqs. (1), (2) and (3). Unified unit, then water phase velocity can be derived:

$v_{\mathrm{w}}=\frac{k_{\mathrm{w}}}{k_{\mathrm{g}}} \times \frac{\mu_{\mathrm{g}}}{\mu_{\mathrm{w}}} v_{\mathrm{g}}+1.157 \times 10^{-17} \beta \rho_{\mathrm{g}} v_{\mathrm{g}}^{2} \frac{k_{\mathrm{w}}}{\mu_{\mathrm{w}}}$

where

$v_{\mathrm{g}}=\frac{q}{2 \pi h r}$

$\beta$ can be calculated (Li and Engler 2001) as follows:

$\beta=\frac{1.15 \times 10^{7}}{k_{\mathrm{g}} \phi}$

Considering influences of irreducible water saturation $\left(S_{\mathrm{wi}}\right)$, residual gas saturation $\left(S_{\mathrm{gr}}\right)$, and sulfur saturation $\left(S_{\mathrm{s}}\right)$, then a water breakthrough time is:

$\mathrm{d} t=\frac{\phi\left(1-S_{\mathrm{wi}}-S_{\mathrm{gr}}-S_{\mathrm{s}}\right)}{v_{\mathrm{w}}} \mathrm{d} r$

Combining Eqs. (4)-(7):

$$
\begin{aligned}
\mathrm{d} t= & \frac{4 \pi^{2} h^{2}}{q^{2}} \frac{\mu_{\mathrm{w}}}{k_{\mathrm{w}}} \phi\left(1-S_{\mathrm{wi}}-S_{\mathrm{gr}}-S_{\mathrm{s}}\right) \\
& \left(\frac{r^{2}}{\frac{\mu_{\mathrm{g}}}{k_{\mathrm{g}}} \times \frac{2 \pi h}{q} r+1.157 \times 10^{-17} \beta \rho_{g}}\right) d r
\end{aligned}
$$

when it is $r_{\mathrm{a}}=L\left(t_{\mathrm{p}}=0\right)$ before producing. A water breakthrough time formula considering sulfur deposition and non-Darcy is obtained by integrating from Eq. (8):

$$
\begin{aligned}
t_{\mathrm{p}}= & M_{\mathrm{gw}} \times \frac{\pi h \phi}{q}\left(1-S_{\mathrm{wi}}-S_{\mathrm{gr}}-S_{\mathrm{s}}\right) L^{2}-1.157 \\
& \times 10^{-17} \beta \rho_{\mathrm{g}} \phi\left(1-S_{\mathrm{wi}}-S_{\mathrm{gr}}-S_{\mathrm{s}}\right) M_{\mathrm{gw}} \frac{k_{\mathrm{g}}}{\mu_{\mathrm{g}}} L \\
& +1.339 \times 10^{-34} \beta^{2} \rho_{\mathrm{g}}^{2} \phi\left(1-S_{\mathrm{wi}}-S_{\mathrm{gr}}-S_{\mathrm{s}}\right) \\
& M_{\mathrm{gw}} \frac{k_{\mathrm{g}}^{2}}{\mu_{\mathrm{g}}^{2}} \frac{q}{2 \pi h} \ln \left(\frac{\mu_{\mathrm{g}}}{k_{\mathrm{g}}} \frac{2 \pi h}{q} L+1.157 \times 10^{-17} \beta \rho_{\mathrm{g}}\right)
\end{aligned}
$$

where $M_{\mathrm{gw}}$ is gas-water mobility ratio:

$M_{\mathrm{gw}}=\frac{k_{\mathrm{gwi}} \mu_{\mathrm{w}}}{k_{\mathrm{wgr}} \mu_{\mathrm{g}}}$

A water breakthrough time formula only considering sulfur deposition is (it is at Darcy state):

$t_{\mathrm{p}}=M_{\mathrm{gw}} \frac{\pi h \phi\left(1-S_{\mathrm{wi}}-S_{\mathrm{gr}}-S_{\mathrm{s}}\right)}{q} L^{2}$

In order to simplify and obtain the relationship between water breakthrough time and sulfur saturation, the sulfur saturation and production of the model were calculated and simplified. In addition, the problem of sulfur saturation $\left(S_{\mathrm{s}}\right)$ and production $(q)$ should be solved in Eq. 10, because sulfur saturation damage reservoir permeability affects the productivity of gas well.

\section{The solution of the model}

This model assumed that the gas reservoir did not appear sulfur precipitation under the condition of the original pressure, as well as the quality of elemental sulfur in the gas, was changed due to pressure drop in solubility (dc) at $r$ (radial distance). Precipitated sulfur quality can be expressed as:

$\mathrm{d} m=2 \pi r h \phi\left(1-S_{\mathrm{wi}}\right) \mathrm{d} r \mathrm{~d} c$

The sour gas reservoir pore volume:

$\mathrm{d} V_{\mathrm{s}}=\frac{2 \pi r h \phi\left(1-S_{\mathrm{wi}}\right) \mathrm{d} r \mathrm{~d} c}{\rho_{\mathrm{s}}}$

Elemental sulfur saturation:

$\mathrm{d} S_{\mathrm{s}}=\frac{\mathrm{d} V_{s}}{2 \pi r h \phi \mathrm{d} r}=\frac{\left(1-S_{\mathrm{wi}}\right) \mathrm{d} c}{\rho_{\mathrm{s}}}$

Equation (13) is changed to:

$\frac{\mathrm{d} S_{\mathrm{s}}}{\mathrm{d} p}=\frac{\left(1-S_{\mathrm{wi}}\right)}{\rho_{\mathrm{s}}} \frac{\mathrm{d} c}{\mathrm{~d} p}$

Based on the principles of associative law and entropy, an empirical equation was obtained utilizing Brunner experimental data (Brunner and Woll 1980). 
$\frac{\mathrm{d} c}{\mathrm{~d} p}=4\left(\frac{M_{\mathrm{a}} \gamma_{\mathrm{g}}}{\mathrm{ZRT}}\right)^{4} \exp \left(\frac{-4666}{T}-4.5711\right) p^{3}$

Combining Eqs. (14) and (15):

$\frac{\mathrm{d} S_{\mathrm{s}}}{\mathrm{d} p}=\frac{\left(1-S_{\mathrm{wi}}\right)}{\rho_{\mathrm{s}}} 4\left(\frac{M_{\mathrm{a}} \gamma_{\mathrm{g}}}{\mathrm{ZRT}}\right)^{4} \exp \left(\frac{-4666}{T}-4.5711\right) p^{3}$

To conveniently calculate:

$A=\frac{\left(1-S_{w i}\right)}{\rho_{s}} 4\left(\frac{M_{a} \gamma_{g}}{Z R T}\right)^{4} \exp \left(\frac{-4666}{T}-4.5711\right)$

Equation (16) is changed to:

$\mathrm{d} S_{\mathrm{s}}=A p^{3} \mathrm{~d} p$

Equations (18) can be changed into (19) by integral.

$S_{\mathrm{s}}=\frac{A}{4}\left(p_{\mathrm{i}}^{4}-p^{4}\right)$

while

$k_{\mathrm{g}}=k_{\mathrm{a}} k_{\mathrm{rg}}$

Elemental sulfur may precipitate when pressure drops below a critical pressure. Given the effects of deposited sulfur on reservoir permeability, an empirical equation about relative permeability and sulfur saturation was provided (Roberts 1997).

$k_{\mathrm{rg}}=\exp \left(\alpha S_{\mathrm{s}}\right)$

Combining with Eqs. (20), (21) and (19), effective reservoir permeability:

$k_{\mathrm{g}}=k_{\mathrm{a}} \exp \left(\frac{\alpha A}{4}\left(p_{\mathrm{i}}^{4}-p^{4}\right)\right)$

Combining Eqs. (1), (5) and (22), following equation can be derived:

$$
\begin{aligned}
& \int_{p_{\mathrm{i}}}^{p_{\mathrm{w}}} k_{\mathrm{a}} \exp \left(\frac{\alpha A}{4}\left(p_{\mathrm{i}}^{4}-p^{4}\right)\right) \mathrm{d} p \\
& \quad=\frac{q \mu_{\mathrm{g}}}{2 \pi h}\left(\ln L-\ln r_{\mathrm{w}}\right)+\frac{1.15 \times 10^{7}}{\phi} \frac{q^{2} \rho_{\mathrm{g}}}{4 \pi^{2} h^{2}}\left(\frac{1}{r_{\mathrm{w}}}-\frac{1}{L}\right)
\end{aligned}
$$

Let:

$$
\begin{aligned}
C & =\int_{p_{\mathrm{i}}}^{p_{\mathrm{w}}} k_{\mathrm{a}} \exp \left(\frac{\alpha A}{4}\left(p_{\mathrm{i}}^{4}-p^{4}\right)\right) \mathrm{d} p \\
D & =\frac{\mu_{\mathrm{g}}}{2 \pi h}\left(\ln L-\ln r_{\mathrm{w}}\right) \\
E & =\frac{1.15 \times 10^{7}}{\phi} \frac{\rho_{\mathrm{g}}}{4 \pi^{2} h^{2}}\left(\frac{1}{r_{\mathrm{w}}}-\frac{1}{L}\right)
\end{aligned}
$$

Equation (23) is changed to:
$E q^{2}+D q-C=0$

A production formula considering sulfur deposition and non-Darcy is obtained by extract roots formula from Eq. (27):

$q=\frac{-D+\sqrt{D^{2}+4 E C}}{2 E}$

\section{Case calculation and analysis}

A gas well was adopted (Table 1) from of Puguang Gas Field, and the effects of some parameters are analyzed via the newly established water breakthrough time model. According to the gas well test report, the parameters are shown in Table 1:

\section{The effect of bottom hole pressure on sulfur deposition and water breakthrough time}

Figure 2 shows the differences between the newly established model, and Wang's and Wu's model. A good trend found between them in Fig. 3 reveals that the validity of the proposed model is verified by comparing the existing models available. From this comparison, it can be seen in Fig. 3 that this new model, which takes sulfur deposition into consideration, shows a shorter water breakthrough time. Because the new model takes into account the effect of sulfur deposition on the reservoir effective permeability and other two models are not considered it. The deposition of sulfur can accelerate gas well water breakthrough, and the two models are deemed to be no longer suitable for modeling the behavior of a high-sulfur gas reservoir.

Figure 2 also shows the relationship between bottom hole pressure and water breakthrough time and sulfur deposition when distance between gas well and edge water is $300 \mathrm{~m}$. The results reveal that the bigger bottom hole pressure is, the smaller sulfur deposition is, and water breakthrough time is longer. In the early gas reservoir development, when the BHP is higher, the higher pressure drop is, the greater gas flow rate is, the bigger rate of sulfur deposition is, and the more obvious decrease in water breakthrough time is. But in the late gas reservoir exploitation, the bottom hole pressure is smaller, the smaller the pressure drop is, the rate of sulfur deposition decreases and the water breakthrough time of gas reservoir changes less.

\section{The effect of sulfur saturation on water breakthrough time}

Figure 3 shows the relationship between sulfur saturation and water breakthrough time in different distances between 
Table 1 Basic parameters of the sour gas well

\begin{tabular}{llll}
\hline Basic parameters & Value & Basic parameters & Value \\
\hline Reservoir temperature (K) & 355.4 & Sulfur density $\left(\mathrm{kg} / \mathrm{m}^{3}\right)$ & 2070 \\
Reservoir initial pressure (MPa) & 48.5 & Z-factor & 0.98 \\
Reservoir porosity (\%) & 8.5 & Residual gas saturation & 0.19 \\
Reservoir absolute permeability $\left(\mu \mathrm{m}^{2}\right)$ & $7.42 \times 10^{-3}$ & Gas-water mobility ratio & 42.05 \\
Gas relative density & 0.83 & Irreducible water saturation & 0.24 \\
Gas viscosity (Pa s) & $2.88 \times 10^{-5}$ & Well radius $(\mathrm{m})$ & 0.1 \\
Water viscosity (Pa s) & $3.3 \times 10^{-4}$ & & \\
\hline
\end{tabular}

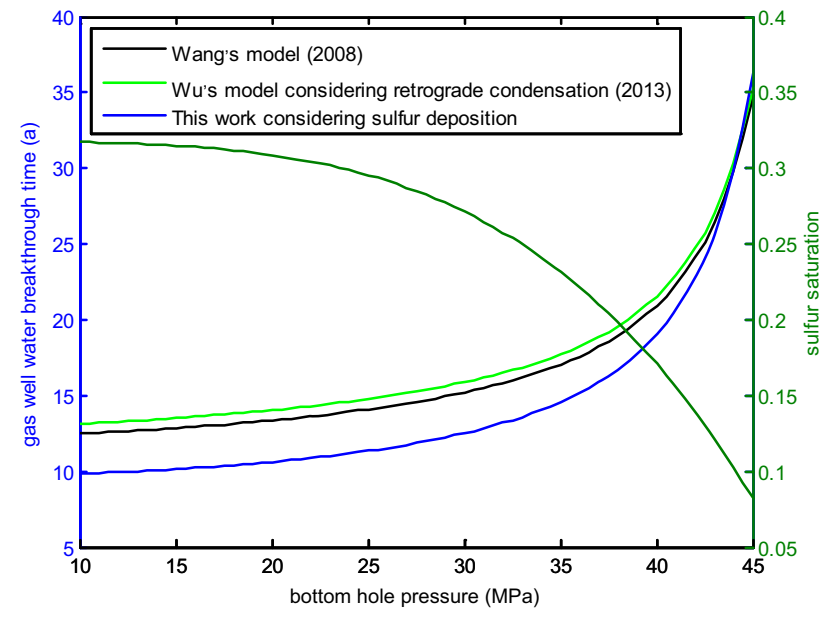

Fig. 2 The effect of bottom hole pressure on sulfur saturation and water breakthrough time

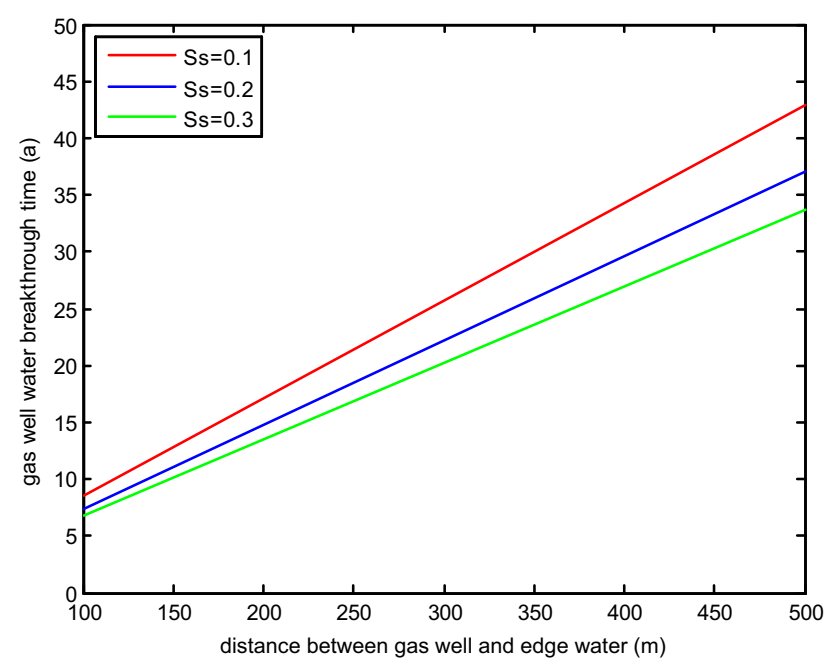

Fig. 3 The effect of sulfur deposition on water breakthrough time

gas well and edge water. The larger the amount of final sulfur deposition in the pore is, the shorter the water breakthrough time, which shows that the sulfur deposition can accelerate the water breakthrough time and has a negative effect on the gas reservoir development. Mainly because the final sulfur deposition in the pore is greater, the greater damage to reservoir permeability and the greater pressure drop is, the greater the flow rate of gas reservoir is, bring the shorter the water breakthrough time. Also it can be seen from Fig. 3, the farther the distance between gas well and water boundary is, the more obvious negative effect of sulfur deposition on the water breakthrough time. The longer the distance between gas well and water boundary is, the more serious the pressure loss of gas reservoir is, the greater pressure drop and the more sulfur precipitation is. And precipitated sulfur accelerates gas well water breakthrough. So, precipitated sulfur has a more negative effect on water breakthrough time in a long distance between gas well and edge water.

\section{The effect of flow state on water breakthrough time}

Figure 4 shows the relationship between flow state and water breakthrough time for different distances between gas well and edge water when bottom hole pressure is $35 \mathrm{MPa}$. The water breakthrough time increases with increasing distance between gas well and edge water.

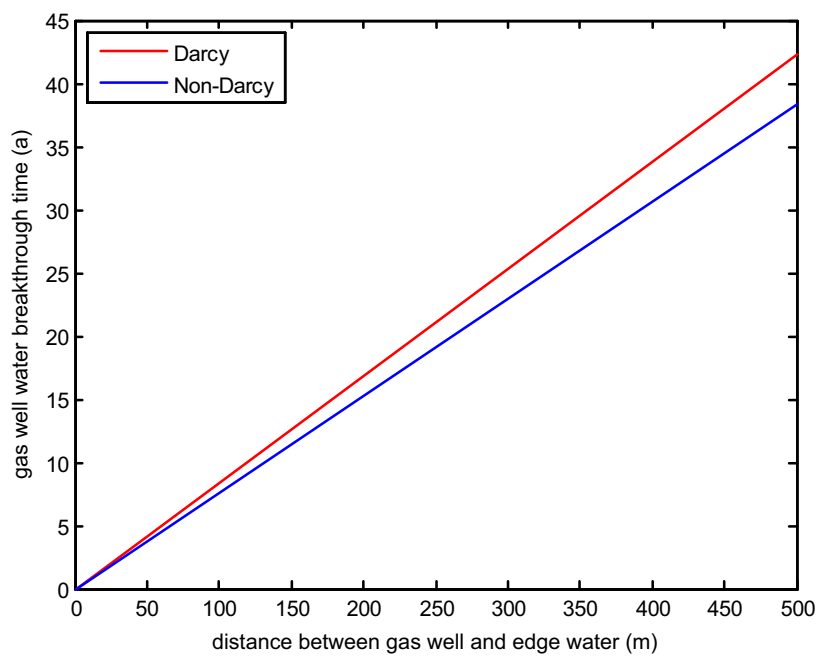

Fig. 4 The effect of flow state on water breakthrough time 
When it is a constant value of distance between gas well and edge water, the water breakthrough time of non-Darcy is shorter than that with Darcy flow. The longer between gas well and edge water is, the more obvious effect of nonDarcy on water breakthrough time is. The reason may be that the high-speed non-Darcy flow produces an increase in pressure drop, which will lead to an increase in sulfur precipitation and water flow velocity, further accelerating gas well water breakthrough. Therefore, the effect of nonDarcy flow on water breakthrough time should not be ignored.

\section{Conclusion}

(1) Based on theory of fluids flow in porous media, a new prediction method of edge water breakthrough time in high-sulfur gas reservoir was proposed. Compared this model with other prediction models, this water breakthrough time prediction model can effectively predict the water breakthrough time for high-sulfur gas reservoir with edge water, and the trend is closer.

(2) The bottom hole pressure has influence on the sulfur deposition and water breakthrough time. The lower bottom hole pressure is, the more the amount of released sulfur and the shorter water breakthrough time is. Precipitated sulfur damages reservoir permeability and diminishes effective seepage distance, which accelerates gas well water breakthrough. The longer the distance between gas well and water boundary is, the more serious the pressure loss of gas reservoir is, the greater pressure drop and the more sulfur precipitation is. So, precipitated sulfur has a more negative effect on water breakthrough time in a long distance between gas well and edge water.

(3) The water breakthrough time increases with increasing distance between gas well and edge water. When it is a constant value of distance between gas well and edge water, the water breakthrough time of nonDarcy is shorter than that of Darcy flow. The longer between gas well and edge water is, the more obvious effect of non-Darcy on water breakthrough time is. Therefore, the non-Darcy flow also can accelerate gas well water breakthrough.

Acknowledgement This work was supported by National Science and Technology Major Project (2016ZX05017-005). The authors recognize the support of State Key Laboratory of Oil and Gas Reservoir Geology and Exploitations (Southwest Petroleum University) for the permission to publish this article.

Open Access This article is distributed under the terms of the Creative Commons Attribution 4.0 International License (http:// creativecommons.org/licenses/by/4.0/), which permits unrestricted use, distribution, and reproduction in any medium, provided you give appropriate credit to the original author(s) and the source, provide a link to the Creative Commons license, and indicate if changes were made.

\section{References}

Brunner E, Woll W (1980) Solubility of sulfur in hydrogen sulfide and sour gases. SPE J 20(5):377-384. doi:10.2118/8778-PA (SPE 8778-PA)

Huang QH, Lu Y, Lu C (2016) Bottom water reservoir with partition prediction method of water breakthrough time. Lithol Reserv 28(4):82-87

Li T (2014) Characteristics of water influx in the development of the Puguang Gas Field, Sichuan Basin. Nat Gas Ind 34(6):65-71

Li D, Engler TW (2001) Literature review on correlations of the nondarcy coefficient. In: SPE Permian Basin Oil and Gas Recovery Conference. Society of Petroleum Engineers, Midland, Texas

Li Y, Li H, Li Y (2015) Prediction method of bottom water coning profile and water breakthrough time in bottom water reservoirwithout barrier. Math Probl Eng 2015(1):1-6

Liu AH, Han YK, Liang HJ (2015) Water invasion identification and water production mode in gas well in Puguang Gas Field. Spec Oil Gas Reserv 22(3):125-127

Roberts BE (1997) The effect of sulfur deposition on gas well inflow performance. SPE Reserv Eng 12(2):118-123. doi:10.2118/ 36707-PA (SPE 36707)

Wang HQ, Li XP, Wu F (2008) Prediction of water breakthrough time in gas reservoirs with edge water. Spec Oil Gas Reserv 15:73-74

Wang SP, Kong FQ, Peng XL, Zhang S (2011) Optimization of the development indexes of the Puguang Gas Field. Nat Gas Ind 31(3):5-8

Wu K, Li X (2013) A new method to predict water breakthrough time in an edge water condensate gas reservoir considering retrograde condensation. Pet Sci Technol 17(32):1738-1743

Yang F, Fan P, He J (2013) An approach to predict water breakthrough time in high gas rate wells of gas reservoirs with edge water. Sci Technol Eng 13(29):8745-8749

Yu QK, Su YX, Li ZH (2016) Establishment of water invasion identification standard for Puguang fracture pore type gas reservoir. Petrochem Technol 23(5):191

Zeng DQ, Peng XL, Liu ZY (2013) Characterization methods of reefbeach facies reservoirs in the Puguang Gas Field. Nat Gas Ind 31(3):9-13

Zhang LH, Li Y, Li XP (2004) New method to predict condensing effect on water breakthrough in condensate reservoirs with bottom water. Nat Gas Ind 24:74-75 